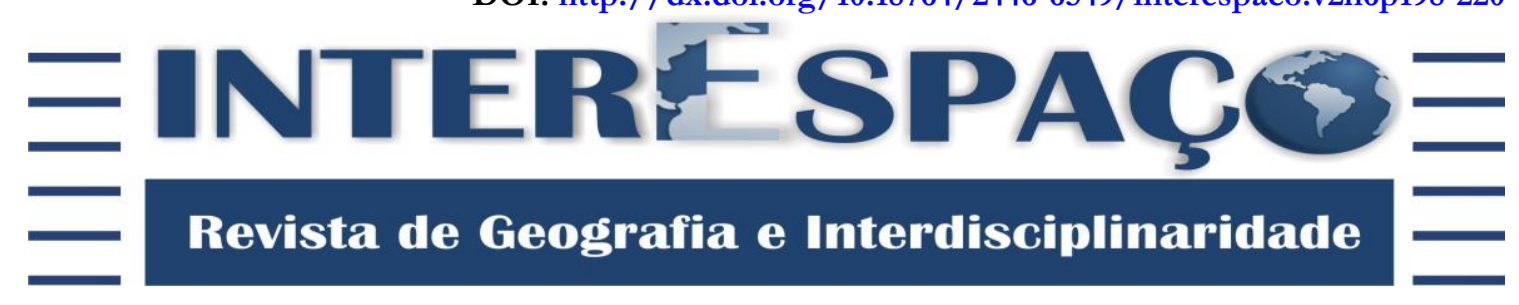

\title{
POLUIÇÃO SONORA NA AVENIDA MINISTRO JOÃO ALBERTO NA CIDADE DE BARRA DO GARÇAS-MT
}

\author{
Romário Rosa de Sousa \\ Mestre em Geografia pela Universidade Federal de Mato Grosso - UFMT. Professor do \\ Departamento de Geografia da Universidade Federal de Mato Grosso - UFMT. \\ romarioufg@yahoo.com.br
}

\begin{abstract}
RESUMO
Este trabalho teve como objetivo principal analisar a emissão de ruídos ambientais na Avenida Ministro João Alberto, na cidade de Barra do Garças-MT, sendo a coleta de dados para a avaliação acústica realizada no dia três de fevereiro de 2015, das 07h00min às $19 \mathrm{~h} 00 \mathrm{~min}$, totalizando uma medição diária de doze horas seguidas dentro do perímetro urbano. Os dados foram coletados de forma simultânea e sem interrupção, diagnosticando, assim, grandezas acústicas. Como resultado, percebeu-se que o veículo automotor caminhão guincho apresentou o maior nível de ruído, registrando aproximadamente 98,0 decibéis, seguido, nessa ordem, pelos seguintes veículos automotores: caminhão, carreta, ônibus, motocicleta, carro de passeio e caminhonete, este último apresentando-se como a menor fonte emissora de ruído, com registro aproximado de 89,0 decibéis. Constatou-se que os valores confirmados dos níveis de ruídos registrados na observaçã̃o diária ultrapassaram o nível permitido por lei. Assim, os níveis de pressão sonora identificados nos pontos de coleta de dados, por estarem todos acima dos valores toleráveis, geram riscos de perda auditiva em trabalhadores que atuem e permaneçam nesses locais.
\end{abstract}

Palavras-chave: Ruído Ambiental; Decibéis dB(A); Diagnóstico; Poluição Sonora.

\section{NOISE IN THE AVENUE MINISTER JOÃO ALBERTO IN THE CITY OF BARRA DO GARÇAS-MT}

\section{ABSTRACT}

This study was meant to examine the emission of environmental noise on Avenida Minister João Alberto, in the town of Barra do Garças- MT, and data collection for the acoustic evaluation held on February 3, 2015, from 07:00 to 19h00min, totaling a daily measurement twelve hours straight within the city limits. Data were collected simultaneously and without interruption, diagnosing thus acoustic quantities. As a result, it was noticed that the motor vehicle tow truck had the highest noise level, registering approximately 98.0 decibels, followed, in that order, the following motor vehicles: truck, trailer, bus, motorcycle, passenger car and truck, the latter presenting itself as the lowest emission source of noise, with an approximate record of 89.0 decibels. It was found that the figures confirmed the noise levels recorded in the daily observation exceeded the level allowed by law. Thus, the sound pressure levels identified in the data collection points, because they are all above tolerable values, generate hearing loss risk in workers that operate and remain in those locations.

Keywords: Environmental Noise; Decibels dB(A); Diagnosis; Noise Pollution. 


\title{
CONTAMINACIÓN ACÚSTICA EN LA AVENIDA MINISTRO JOÃO ALBERTO EN LA CIUDAD DE BARRA DO GARÇAS-MT
}

\begin{abstract}
RESUMEN
Este estudio estaba destinado a examinar la cuestión del ruido ambiental en Ministro Avenida João Alberto, en la población de Barra do Garças - MT, y la recogida de datos para la evaluación acústica celebrada el 3 de febrero de 2015, de 07:00 a 19h00min, por un total de unos diarios de medición doce horas seguidas dentro de los límites de la ciudad. Los datos fueron obtenidos de forma simultánea y sin interrupción, para diagnosticar grandiosidades acústicas. Como resultado, se ha dado cuenta de que el vehículo de motor camión de remolque tenía el nivel de ruido más alto, registrando aproximadamente 98,0 decibelios, seguida, por este orden, los siguientes vehículos de motor: camiones de remolques, autobuses, motocicletas, automóviles de pasajeros y camiones, este último se presenta como la fuente de emisión más baja de ruido, con un registro aproximado de 89,0 decibelios. Se encontró que las cifras confirman los niveles acústicos registrados en la observación diaria superaron el nivel permitido por la ley. Por lo tanto, los niveles de presión sonora identificados en los puntos de recogida de datos, ya que son todos por encima de los valores tolerables, generan riesgo de pérdida de audición de trabajadores que operan y permanecen en esos lugares.
\end{abstract}

Palabras-clave: Ruido Ambiental; Decibeles dB(A); El Diagnóstico; La Contaminación Acústica.

\section{INTRODUÇÃO}

Segundo Manoel Ruiz (2008, p. 10), a globalização ou mundialização é a interdependência de todos os povos e países do nosso planeta, também denominado “aldeia global". As notícias do mundo são divulgadas pelos jornais, rádio, televisão, internet, e outros meios de comunicação mais modernos. Com toda essa tecnologia a serviço da humanidade, tem-se a impressão que o planeta terra ficou menor. Pode-se também observar que os bens de consumo, a moda, a medicina, enfim, a vida do ser humano sofre influência direta da globalização.

Considerando, então, a velocidade e a disseminação da informação, a população está se atentando para problemas antes relacionados apenas à comunidade científica, tais como os atinentes às alterações ambientais.

Os problemas ambientais estão se tornando cada vez mais relevantes e discutidos na atualidade. Porém, o que hoje se chamam agravos ao meio ambiente, na realidade, não é outra coisa senão agravos ao meio de vida do homem, isto é, ao meio visto em sua integralidade. Esses agravos ao meio devem ser considerados dentro do processo evolutivo pelo qual se dá o conforto entre a dinâmica da história e a vida do planeta (SANTOS, 2006). 
Dá-se o nome de poluição a qualquer degradação ambiental, deterioração ou estrago das condições ambientais, do habitat de uma coletividade humana, sendo uma perda, mesmo que relativa, da qualidade de vida em decorrência de mudanças ambientais, desta forma são chamados de poluentes os agentes que provocam a poluição, como um ruído excessivo, um gás nocivo na atmosfera, detritos que sujam os rios ou praias ou um cartaz publicitário que degrada o aspecto visual de uma paisagem (PETIAN, 2008).

Dentre os vários tipos de poluição, pode-se citar a poluição sonora, ambiental ou ocupacional; uma forma de poluição bastante disseminada nas sociedades industrializadas, causadora de perdas auditivas em adultos e crianças, acarretando também comprometimentos não auditivos que afetam a saúde física geral e emocional dos indivíduos (SANTOS, 1994).

Dados históricos apontam que a preocupação com os ruídos tem sido abordada desde 47 a.C., e nas últimas décadas, a poluição sonora se transformou numa das formas de poluição que mais atinge a humanidade, trazendo consequências muitas vezes irreversíveis. (MENDES, 1995).

Estudos da Organização Mundial da Saúde - OMS (2003) apontam que, depois da poluição da água e do ar, nada agride mais os sentidos humanos que a poluição sonora, sendo que este problema ambiental ocupa o terceiro lugar em nível planetário. Os mesmos estudos afirmam que em torno de 15 milhões de pessoas no Brasil tem algum problema de audição. Com isso, o ruído é classificado como a terceira prioridade entre as causas de doenças ocupacionais (FISCHER, 1989).

São altos os níveis de ruído a que as pessoas estão expostas nas cidades grandes, médias e pequenas: nas ruas, no trabalho, nas escolas, no lazer e inclusive em suas residências, podendo alcançar níveis próximos do limiar recomendável ou até mesmo superiores, gerando uma poluição sonora preocupante aos ouvidos dos seres humanos (SIH, 1997).

Babisch (1998) relata que em relação a outros aspectos ambientais, são relativamente poucos os estudos epidemiológicos em relação ao ruído na esfera ambiental. Inúmeros estudos têm sido realizados sobre o ruído, porém a maior parte deles contempla a área ocupacional, avaliando-se trabalhadores expostos durante sua jornada de trabalho ao risco físico do ruído (FONSECA, 2007).

Sabe-se que a exposição prolongada sob ruído ambiental superior aos níveis considerados seguros, sem a devida proteção auditiva poderá causar uma série de danos auditivos, destacando-se em especial a perda auditiva induzida por ruído - PAIR, também 
desconforto sensorial, irritação, estresse, cansaço mental, dificuldades para dormir e outros mais problemas de agravo a saúde humana. Assim, para Rios (2003), na atualidade, envolvidas pelas realizações capitalistas, as pessoas não tem se dado conta dos inúmeros casos de perdas auditivas registrados anualmente por PAIR. Para Sminkey (2015), quando a exposição é particularmente alta, regular ou prolongada, pode levar a danos permanentes das células sensoriais do ouvido, resultando em perda auditiva irreversível.

De acordo com Zannin (2003), os resultados de estudos e pesquisas realizadas por vários estudiosos em todo o território brasileiro mostram que a evolução da poluição sonora em nosso meio vem constituindo uma ameaça ao bem-estar e à saúde dos cidadãos, o que pode ser percebido, inclusive, nos parques e jardins públicos, embora ainda considerados lugares da cidade capazes de oferecerem alívio para as atribulações do cotidiano urbano.

A crescente urbanização tem contribuído para o aumento dos níveis de ruído nas cidades, sendo os ruídos do tráfego, de bares, lanchonetes, lojas, casas noturnas e outras fontes, alguns dos principais responsáveis pela poluição sonora urbana. A exposição de pessoas aos ruídos tem se constituído um fator preocupante para a saúde auditiva de todos. (LACERDA et al., 2010).

Os estudos em países de média e alta renda analisados pela OMS indicam que, entre adolescentes e jovens adultos com idades entre 12 a 35 anos, quase 50\% estão expostos a níveis inseguros de som a partir do uso de dispositivos de áudio pessoal e cerca de $40 \%$ são expostos para níveis potencialmente prejudiciais de som em locais de entretenimento. Níveis elevados de sons podem ser, por exemplo, exposição em excesso de 85 decibéis (dB) para oito horas ou $100 \mathrm{~dB}$ durante 15 minutos (SMINKEY, 2015).

Diante do exposto, enseja-se neste artigo, analisar a emissão de ruídos na Avenida Ministro João Alberto na cidade de Barra do Garças-MT, buscando contribuir não apenas com as discussões no âmbito acadêmico da temática, mas também e principalmente oferecer dados confiáveis dos níveis de poluição sonora ao longo da principal avenida da cidade para posteriores intervenções do poder público.

Far-se-á, a seguir, a descrição da metodologia adotada na pesquisa e a análise dos resultados obtidos na data e no período de aplicação da pesquisa, de modo a perceber os níveis de poluição sonora, que influem na qualidade de vida dos indivíduos. Dessa forma, o artigo está estruturado em coleta dos dados no dia 03/02/2015, no período de $7 \mathrm{~h}$ as $19 \mathrm{~h}$, referentes em quatros pontos de observações, com posterior organização dos dados 
sonoros em planilha eletrônica e extração de um relatório de tabela dinâmica, gerando-se as médias diárias referente a cada ponto observado.

\section{Área de Estudo}

Foi definida, como área de estudo, a cidade de Barra do Garças - MT, localizada às margens do Rio Araguaia no Estado de Mato Grosso, divisa com o Estado de Goiás (conforme a Figura 1).

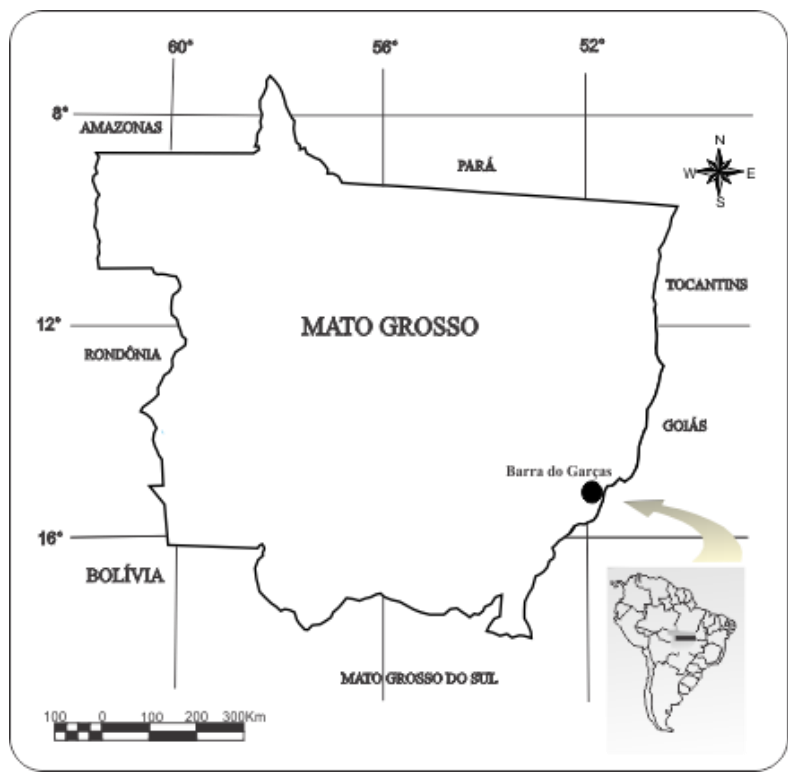

Figura 1 - Localização da área de estudo

Elaboração: Romário Rosa de Sousa (2015).

\section{METODOLOGIA}

Os procedimentos metodológicos foram pautados nas orientações de Rangel; Zanotelli (2002), Nagem (2004) e de Sousa et al. (2012) e desenvolvidos em 6 (seis) etapas distintas, descritas a seguir.

$1^{a}$ Etapa: revisão da literatura e a informações relativas aos casos ocorridos.

$2^{a}$ Etapa: aquisição do equipamento denominado decibelímetro portátil, modelo POL 09, de propriedade da empresa Politerm, tendo passado por calibração, testes acústicos e configuração de acordo com as instruções do fabricante. Foi utilizado o software Enhanced SLM BZ 7125, versão 1.0, e microfone de campo livre de 1/2”, tipo 4188, a este acoplado um protetor de vento, do mesmo fabricante, para minimizar as possíveis interferências causadas por ventos de velocidade superior a 2,0 m/s. Este medidor de nível 
de pressão sonora classifica-se como do tipo 1, de precisão, atendendo aos padrões das normas ANSI S1.43 - 1983, IEC 651 - 1979, IEC 804 - 1985, entre outras.

$3^{\mathbf{a}}$ Etapa: escolha dos locais para realizar as mensurações de acordo com o fluxo de pessoas e trânsito de automóveis dentro do perímetro urbano.

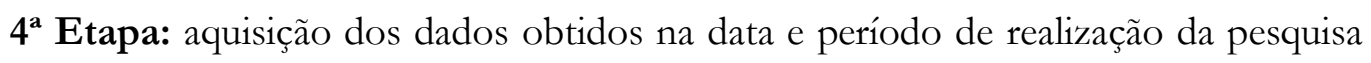
nos pontos de observação, utilizando-se de monitores acústicos fixos, por meio dos quais se obtiveram os níveis de pressão sonora máximos e o nível de exposição sonora de pico, em cada ponto.

5 ${ }^{\text {a }}$ Etapa: coleta dos dados climáticos referente ao dia e período da realização da pesquisa. Foi coletado com o aparelho Datalogging/Printing AZ9871 - Anemometer adquirido da empresa Instrutemp, sendo coletadas temperatura do ar, umidade relativa do ar, velocidade do vento/direção, precipitação e a pressão atmosférica.

$\mathbf{6}^{\mathbf{a}}$ Etapa: tabulação e geração de um banco dos dados em planilha eletrônica, posteriormente dispostos em relatório de tabela dinâmica, com os valores médios e soma.

Em seguida, iniciou-se a determinação do dia, horários e duração das medidas. $\mathrm{Na}$ avaliação do ruído ambiental, o ideal seria que se medisse um período de tempo completo, tal como dias, semanas ou mesmo meses. Nestes casos, as medidas normalmente são obtidas a cada segundo, minuto ou quartos de hora e são utilizadas para se construir a história (distribuição) dos níveis de ruído de um local. Contudo, estas longas medições podem ser caras e difíceis de serem executadas (BRÜEL \& KJÆR, 2000).

Dessa forma, a pesquisa foi realizada no dia três de fevereiro de 2015, no período de $07 \mathrm{~h}$ até as $19 \mathrm{~h}$, totalizando uma medição diária de 12 (doze) horas seguidas realizadas em 4 (quatro) pontos da Avenida Ministro João Alberto dentro perímetro urbano de Barra do Garças-MT. A escolha desta faixa horária diurna teve como objetivo cobrir o horário comercial, tendo sido possível captar a influência dos deslocamentos de veículos e de pessoas antes e depois do horário do expediente.

A cidade de Barra do Garças possui uma população estimada em 2015 de 58.398 habitantes, e tem uma área de territorial de 9.078,984 km², contando com uma densidade demográfica $\left(\mathrm{hab} / \mathrm{km}^{2}\right)$ de 6,23. Assim, de acordo com o Instituto Brasileiro de Geografia e Estatística (2014), a frota de automóveis do município está estimada em 35.649 veículos entre caminhão, caminhonete, camioneta, micro-ônibus, motocicleta, motoneta, ônibus, trator de rodas e utilitário.

Os dados foram coletados de forma simultânea e sem interrupção, diagnosticando assim as grandezas acústicas. As mensurações em ambientes diversificados com 
caracterizações diferentes puderam ser realizadas a uma distância de 7 (sete) metros da fonte emissora de ruído, por uma questão de segurança da equipe e também seguindo as orientações do Conselho Nacional de Trânsito (CONTRAN), e em atendimento a resolução no 1, de 08 de março de 1990.

Os horários de medição foram escolhidos de acordo com as características do ambiente e das fontes sonoras em estudo. A norma ISO 1996/1 (1982) estabelece que a localização dos pontos de medição depende do objetivo das medições.

É importante ressaltar que a Avenida Ministro João Alberto corta o perímetro urbano da cidade de Barra do Garças-MT, e, concomitante, se funde com a BR-158, e BR70, dando acesso às porções nordeste, centro-sul e norte do Estado de Mato Grosso e ainda a porção sudoeste do Estado Goiás, possuindo, assim, um tráfego intenso de carros de passeio, veículos de som automotivos, motocicletas, caminhões, ônibus e carretas de transportes pesados, de diversas modalidades de cargas perigosas, inflamáveis, vivas, molhadas e secas.

De acordo com o Art. $3^{\circ}$ caput da Resolução no 204 de 20 de outubro de 2006, “a medição da pressão sonora de que trata se fará em via terrestre aberta à circulação e será realizada utilizando o decibelímetro" (Figura 2).

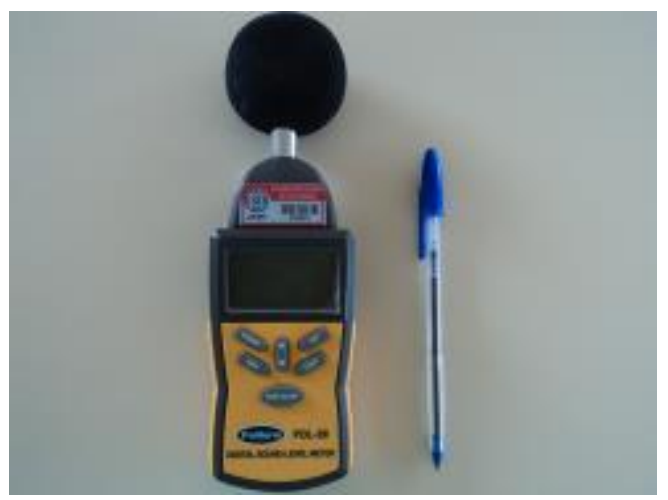

Figura 2 - Equipamento decibilímetro Fonte: Romário Rosa de Sousa (2015).

Para obtenção dos dados, seguiram-se as normas estabelecidas pelo Ministério das Cidades - Conselho Nacional de Trânsito, Resolução no 204/2006, que, no $\$ 1^{\circ}$ do mesmo artigo citado, determina o posicionamento do decibelímetro, dando-lhe uma definição: “o decibelímetro, equipamento de medição de pressão sonora, deverá estar posicionado a uma altura de aproximada de 1,50 m de altura, (um metro e meio) com tolerância de mais ou menos $20 \mathrm{~cm}$ (vinte centímetros) acima do nível do solo e na direção em que for medido o maior nível sonoro". 
Devido ao efeito desagradável provocado pela complexa composição do ruído, mesmo em intensidades inferiores aos limites normativos, não raro, são considerados como poluição sonora. Devido ao caráter subjetivo desta percepção, não existe previsão normativa que permita uma avaliação e controle para tais circunstâncias (BRESSANE et al., 2010).

O nível de pressão sonora equivalente contínuo ponderado em A representa o nível de um som contínuo (estacionário) que, em um intervalo de tempo específico, tem a mesma energia sonora do som em estudo, cujo nível varia com o tempo (ISO 1996/1, 1982). Além de ser utilizado como padrão de análise para o rú́do ambiental, o $L_{\text {Aeq }}$ também é utilizado na avaliação da exposição ao ruído ocupacional. Ele representa o potencial de lesão auditiva do nível variável (oscilante), que depende não somente do seu nível como

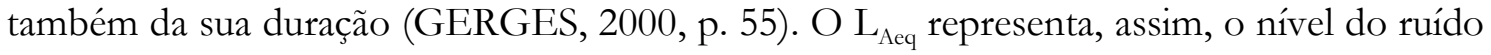
contínuo (fixo) ao qual as pessoas estão sujeitas, em várias situações, devido aos diversos tipos de ruído, sendo equivalente ao ruído original que é variável.

Vale salientar que o decibel equivale a uma relação entre valor usualmente obtidos com medições em campo e valores adotados como referência padrão resultando em uma grandeza adimensional não sendo, portanto, considerado como unidade acústica, mas apenas uma escala logarítmica de referência (IWATA et al., 2015).

\section{RESULTADOS E DISCUSSÃO}

Dentre as diversas formas de poluição ambiental, a poluição sonora é uma das que tem conduzido à deterioração da qualidade de vida nas cidades. A revolução industrial, juntamente com os avanços tecnológicos observados nas últimas décadas, foi responsável pelo acelerado processo de degradação do ambiente em que vivemos. Ao mesmo tempo em que o homem passou a contar com novidades e facilidades no seu dia a dia, houve um grande aumento no número de fontes de poluição (GARCIA, 1994).

Para interromper este processo, as indústrias deverão produzir sem poluir, considerar qualquer impacto que possam causar ao meio ambiente e rever seus métodos de fabricação, considerando, por exemplo, o uso e a conservação do solo e da energia, a não produção de odores, de ruído e de resíduos, e a garantia da saúde ocupacional (CONDE, 1995). Deve-se, assim, tirar partido da tecnologia e da conscientização das pessoas para melhorar a qualidade de vida e para reverter o processo de destruição do meio ambiente (FALETTY, 1994). 
Enquanto esta nova mentalidade de produzir e de viver sem poluir não se torna uma prática comum, o ser humano vem sofrendo os efeitos de suas intervenções e explorações inconsequentes, passando a ter uma vida, muitas vezes, desconfortável, apesar de todos os avanços. O conforto pode ser definido como uma sensação de bem-estar, tendo um caráter subjetivo, e sendo influenciado por uma grande quantidade de fatores (BERTOLI, 2002). A intervenção humana no meio ambiente tem feito com que seja difícil experimentar uma sensação total de conforto, uma vez que distúrbios no clima, a poluição do ar e dos rios, além de poluição visual e sonora estão cada vez mais presentes no cotidiano das pessoas (MAIZ; LEON, 1994).

A presença de um som em um ambiente pode ser desejável quando auxilia, por exemplo, na comunicação, no relaxamento ou no divertimento das pessoas. Entretanto, muitas vezes, o som pode ser indesejável, incomodante e podendo até causar danos temporários ou irreversíveis à saúde e audição, sendo chamado, nestes casos, de ruído (SMINKEY, 2015). A classificação de um som como desagradável é subjetiva e depende das preferências pessoais, de aspectos culturais, da atividade que se desenvolve, do estado de ânimo de quem o escuta e do interesse econômico envolvido (BERISTÁIN, 1998).

São diversos os efeitos produzidos pela exposição ao ruído como surdez temporária ou permanente (perda progressiva na capacidade de se perceber as altas frequências), zumbido no ouvido, falta de tranquilidade, interferência na comunicação, diminuição do desempenho e da concentração, irritabilidade, stress e agressividade são alguns dos danos fisiológicos e psicológicos que podem ocorrer na presença do ruído (BERISTÁIN, 1998). Normalmente, a comunicação verbal, o ensino e a aprendizagem, as atividades mentais e o sono são as situações mais afetadas (GIERKE; ELDRED, 1997).

O ruído ambiental é aquele que se percebe ou que se origina em locais públicos, sendo aquele que causa efeitos coletivos e que interfere na qualidade ambiental de um lugar (COLLADOS, 1998). Ele é resultado da combinação das diversas fontes existentes em uma comunidade (RIVAS, 1994), sendo uma função aleatória e variável, (SLAMA; NIEMEYER, 1998) o que dificulta, muitas vezes, o seu controle.

De acordo com a Norma ISO 1996: Acoustics - Description and measurement of environmental noise, Part 1: Basic quantities and procedures (1982), define-se ruído ambiental como ruído de todas as fontes sonoras, situadas próximas ou afastadas (ruído de tráfego, pássaros, máquinas, etc.).

$\mathrm{Na}$ escala urbana, é muito importante prever o impacto de mudanças no sistema viário no uso do solo e na arquitetura, por exemplo, evitando erros de caráter acústico no 
desenvolvimento e na expansão das cidades (COSTABAL; SEBALLOS, 1994). Neste contexto, o planejamento urbano consciente se torna fundamental. O planejamento urbano tem como objetivo conferir ordem ao desenvolvimento de um espaço e prever soluções para as necessidades futuras. Para que seja bem executado, é importante que se tenha o máximo de informação a respeito das condições, problemas e possibilidades de um determinado lugar (PRINZ, 1980). Em relação à poluição sonora, pode-se planejar a localização de atividades que não necessitem de silêncio, tais como comércio, em áreas pouco tranquilas, ao longo de avenidas ou de vias com grande movimento, criando uma barreira que proteja as zonas mais sensíveis ao ruído do tráfego veicular (MACEDO; SLAMA, 2000). Já as atividades que exigem silêncio devem ser separadas. Em Portugal, por exemplo, só é permitida a implantação de novas áreas residenciais, escolas e hospitais em locais classificados como pouco ruidosos (COELHO et al., 1996).

Para Marchett e Carvalho (2011), a vida dentro dos espaços urbanos, mais do que os fluxos de gente e automóveis, apresenta um movimento de ruídos como sinônimo de som não desejado. De novos ruídos, como as academias de ginástica que se instalam em bairros residenciais ou passam a fazer parte dos projetos de novas edificações e os exercícios são feitos ao som de música alta para marcar o ritmo. O morar em grupo se reflete no aumento da densidade demográfica nos bairros centrais de qualquer cidade, local onde estão também concentradas as atividades comerciais e financeiras.

Nas últimas décadas, à necessidade da conservação do meio ambiente e, consequentemente, da melhora da qualidade de vida da população, tem sido positivada em textos normativos específicos de cunho ambiental, que buscam controlar as intervenções humanas. Preocupação esta consagrada, sobretudo, na Constituição da República Federativa do Brasil de 1988, como se destaca a seguir.

O caput do artigo 225, título VIII, capítulo VI, da Constituição Brasileira, que se refere ao Meio Ambiente, estabelece que "todos têm direito ao meio ambiente ecologicamente equilibrado, bem de uso comum do povo e essencial à sadia qualidade de vida, impondo-se ao poder público e à coletividade o dever de defendê-lo e de preservá-lo para as presentes e futuras gerações" (BRASIL, 1988). Com esta finalidade, o Poder Público, entre outras ações, passa a exigir um estudo de impacto ambiental antes da implantação de qualquer obra ou atividade que possa causar alguma forma de degradação do meio ambiente; passa, também, a controlar a produção, a comercialização e o emprego de técnicas, métodos e substâncias que possam gerar algum risco, além de passar a promover a educação ambiental em todos os níveis de ensino juntamente com a 
conscientização pública para a preservação do meio ambiente (parágrafo $1^{\circ}$, incisos IV a $\mathrm{VI})$.

No âmbito Federal, foram publicadas diversas resoluções pelo Conselho Nacional do Meio Ambiente (CONAMA), estabelecendo normas de preservação do meio ambiente, entre as quais se cita a Resolução n 1 , de março de 1990, que constituiu critérios para o controle de ruídos excessivos. Por essa resolução estabeleceu-se que as atividades geradoras de ruído se obrigam a seguir diretrizes vinculadas à Associação Brasileira de Normas Técnicas (ABNT) e, em se tratando de ruídos gerados por veículos automotores, ao Conselho Nacional de Trânsito (CONTRAN).

Seguindo as normas da legislação vigente citadas anteriormente, realizou-se a coleta de dados de pressão sonora máximo em $\mathrm{dB}(\mathrm{A})$, a uma distância de 7 (sete) metros da fonte emissora de ruído, e também por uma questão de segurança da equipe, conforme a Tabela 1.

\begin{tabular}{cc} 
Tabela 1 - Níveis de pressão sonora $-\mathrm{dB}(\mathrm{A})$ \\
\hline Nível de Pressão Sonora Máximo - $\mathrm{dB}(\mathrm{A})$ & Distância de Medição $(\mathrm{m})$ \\
\hline 104 & 0,5 \\
98 & 1,0 \\
92 & 2,0 \\
86 & 3,5 \\
80 & 7,0 \\
77 & 10,0 \\
74 & 14,0 \\
\hline
\end{tabular}

Fonte: Conselho Nacional de Trânsito - CONTRAN (2014)

Modificado por: Romário Rosa de Sousa (2014).

Ressalta-se que na cidade de Barra do Garças-MT, o maior fluxo de trânsito ocorre ao longo da Avenida Ministro João Alberto, com o trafego intenso de veículos automotores.

No ponto 1 (um) (Tabela 2), observou-se que o veículo caminhão guincho atingiu o maior valor, a saber: 97,80 decibéis de ruído, seguido, nessa ordem, do veículo de transporte pesado denominado carreta, com 93,39 decibéis, do veículo de transporte caminhão: 93,03 decibéis, de veículos como ônibus, registrando o valor de 91,32 decibéis, da modalidade de veículo motocicleta, com 89,89 decibéis, caminhonete, com 85,80 decibéis, e, finalmente, carros de passeio, com 85,28 decibéis. Em suma, no ponto 1, o valor geral de ruídos (total geral) foi de 91,36 decibéis. 
Poluição sonora na Avenida Ministro João Alberto na cidade de Barra do Garças-MT Romário Rosa de Sousa

Tabela 2 - Valores médios em $\mathrm{dB}(\mathrm{A})$, dos pontos de observações

\begin{tabular}{c|cccccccc}
\hline Ponto & Caminhão & $\begin{array}{c}\text { Caminhão } \\
\text { Guincho }\end{array}$ & Caminhonete & Carreta & $\begin{array}{c}\text { Carro } \\
\text { de } \\
\text { passeio }\end{array}$ & Motocicleta & Ónibus & $\begin{array}{c}\text { Total } \\
\text { Geral }\end{array}$ \\
\hline 1 & 93,03 & 97,80 & 85,80 & 93,39 & 85,28 & 89,89 & 91,32 & 91,36 \\
2 & 94,33 & - & 92,20 & 92,56 & 93,32 & 91,78 & 92,00 & 92,85 \\
3 & 93,27 & - & 89,11 & 94,40 & 87,81 & 92,77 & 92,39 & 92,70 \\
4 & 92,65 & - & 91,65 & 92,66 & 92,99 & 92,70 & 92,53 & 92,66 \\
\hline
\end{tabular}

Organizador: Romário Rosa de Sousa (2015).

Constatou-se no ponto 2 (dois) que o maior valor registrado, de 94,33 decibéis de ruído, foi provocado pela categoria caminhão, seguido pelos carros de passeio, com 93,32 decibéis, caminhonete, com 92,20 decibéis, carretas, com 92,56 decibéis, ônibus, com 92,00 decibéis, e, finalmente, com 91,78 decibéis, a motocicleta. Nesse ponto, o valor geral foi de 92,85 decibéis.

Ainda analisando a tabela 2 , avaliou-se no ponto 3 (três), que o veículo que provoca maior poluição sonora é o veículo de transporte carreta, para o qual registrou-se 94,40 decibéis, seguido, respectivamente, com 93,27 decibéis, pelo veículo de transporte pesado carreta, pela motocicleta, registrando 92,77 decibéis, pela categoria ônibus, com 92,39 decibéis de ruído, pela modalidade caminhonete, com 89,11 decibéis, e, por último, com 87,81 decibéis, pela emissão de ruído do veículo de transporte carro de passeio.

No que diz respeito às aferições do ponto $\mathrm{n}^{\circ} 4$, os veículos de transporte carro de passeio registraram o maior índice de ruído, com 92,99 decibéis, seguindo-se, com 92,70 decibéis de ruído, pela modalidade motocicleta, pelos veículos de transportes pesados carretas, com valor de 92,66 decibéis, pelo veículo caminhão, com 92,65 decibéis, pela modalidade de veículo ônibus com 92,53 decibéis, e, por fim, pelos veículos caminhonete, com 91,65 decibéis.

No Quadro 1, demonstram-se as médias meteorológicas a partir dos dados coletados no momento do registro das grandezas acústicas, averiguando-se os valores médios meteorológicos demonstraram que os ruídos sonoros se dissiparam de forma fácil e sem encontrar nenhuma barreira para sua propagação.

Quadro 1 - Médias dos dados meteorológicos

\begin{tabular}{|c|c|c|c|c|}
\hline T. do ar $^{\circ} \mathrm{C}$ & UR do ar $\%$ & $\begin{array}{c}\text { P. Atmosférica } \\
\mathrm{hPa}\end{array}$ & Dir. do vento & $\begin{array}{c}\text { Vel. do vento } \\
\mathrm{m} / \mathrm{s}\end{array}$ \\
\hline 30,3 & 61,6 & 974,6 & oeste e sul & 1,2 \\
\hline
\end{tabular}

Organizador: Romário Rosa de Sousa (2015). 
Poluição sonora na Avenida Ministro João Alberto na cidade de Barra do Garças-MT Romário Rosa de Sousa

Analisando o quadro 1, notou-se que a temperatura do ar foi de $30,3^{\circ} \mathrm{C}$, a unidade relativa do ar 61,6\%, a pressão atmosférica $974,6 \mathrm{hPa}$, a direção do vento oscilou para o oeste e sul, já a velocidade do vento ficou em $1,2 \mathrm{~m} / \mathrm{s}$.

Convém ressaltar que as coletas dos dados meteorológicos ocorreram na mesma data e nos mesmos locais dos registros das grandezas acústicas, nos horários sinóticos de $9 \mathrm{~h} 00 \mathrm{~min}$ e $15 \mathrm{~h} 00 \mathrm{~min}$.

Sobre a localização dos pontos em que a coleta ocorreu, o ponto 1 (um) está localizado nas proximidades da escola estadual de ensino básico "Eurico Gaspar Dutra", frequentada nos turnos de manhã, tarde e noite, por crianças, adolescentes, jovens e adultos de todas as faixas etárias. Assim, o fluxo de pessoas nesta localidade é intenso, dada a existência ainda de agência bancária, lojas, posto de gasolina, parada de transporte urbano e residências (Figura 3).
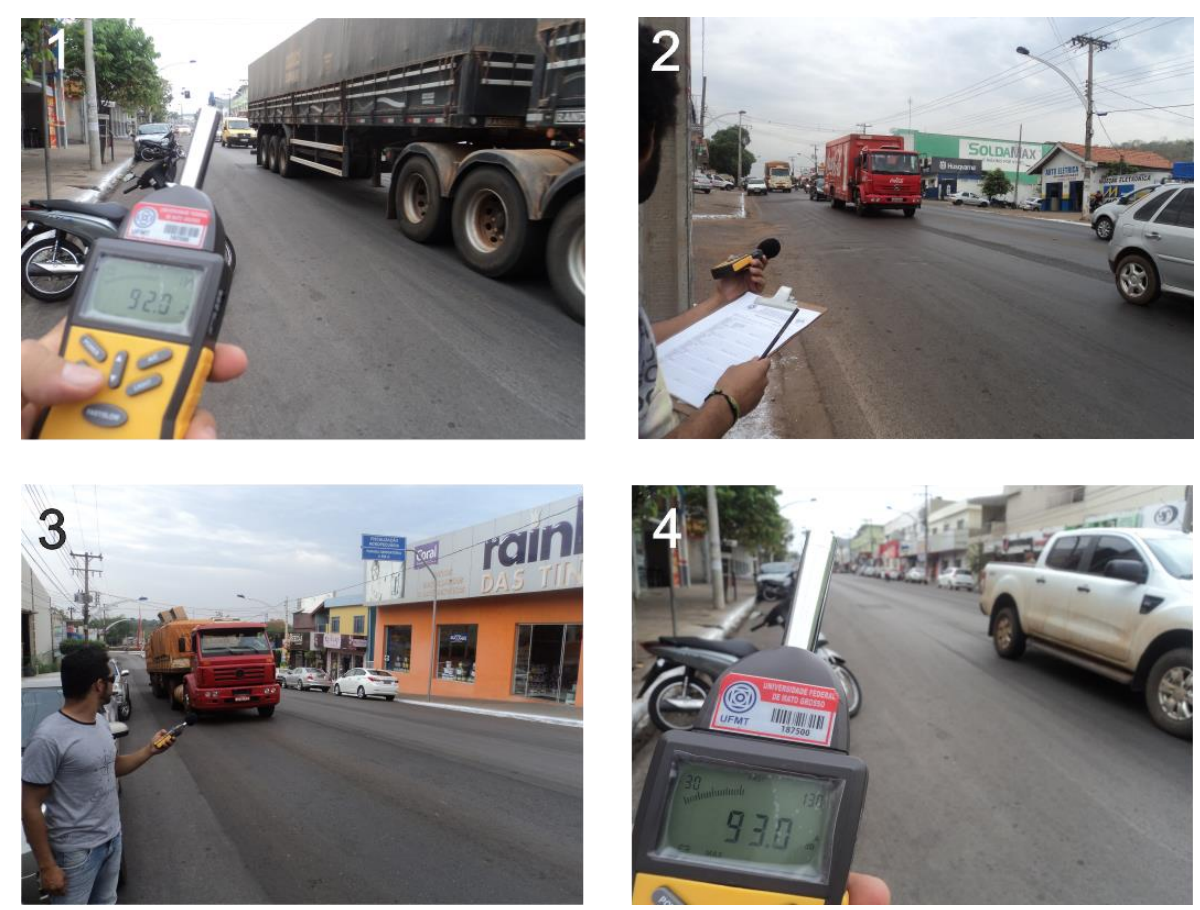

Figura 3 - Pontos de observações com equipamento Decibilímetro Fonte: Romário Rosa de Sousa (2015).

O ponto 2 (dois), figura 3, localiza-se nas proximidades de uma subestação rodoviária, com parada de ônibus intermunicipal e urbano, bastante movimentada em todos os turnos e por pessoas de todas as faixas etárias, onde também há um banco, igrejas, lojas e residências concentrando um grande números de pessoas.

$\mathrm{Na}$ Figura 4, visualizou-se os pontos 1 e 2, onde foram realizadas as observações ao longo da avenida Ministro João Alberto. 


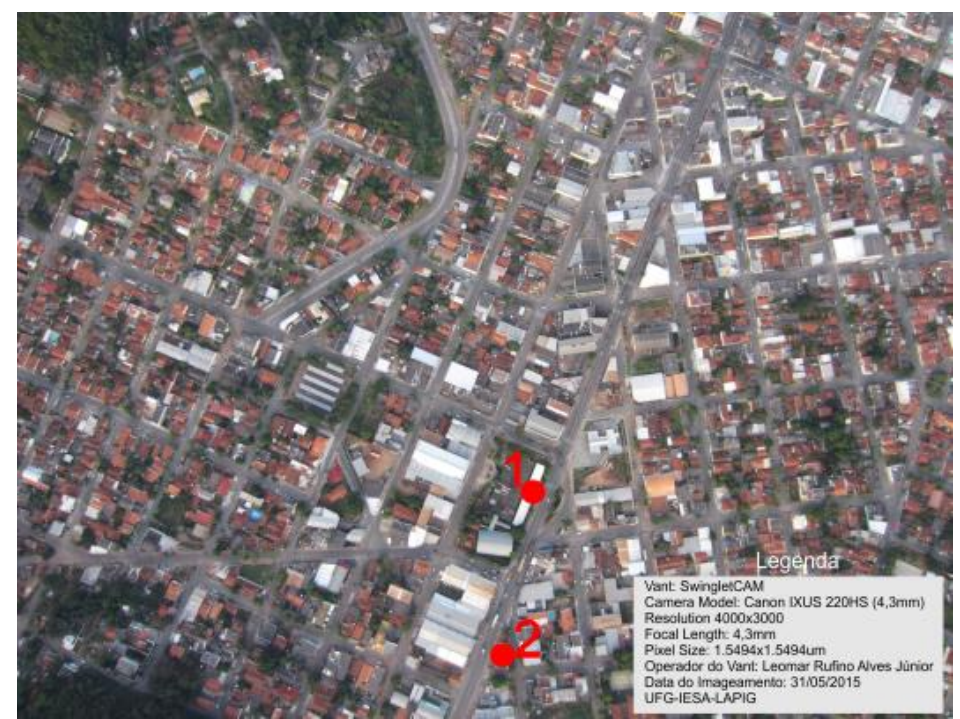

Figura 4 - Imagem dos os pontos 1 e 2 Fonte: Romário Rosa de Sousa (2015).

Nas proximidades do ponto 3, há uma parada de ônibus urbano, também com fluxo intenso de pessoas nesta localidade, devido também a existência de estabelecimentos como bancos, lojas, farmácias e residências (Figura 5).

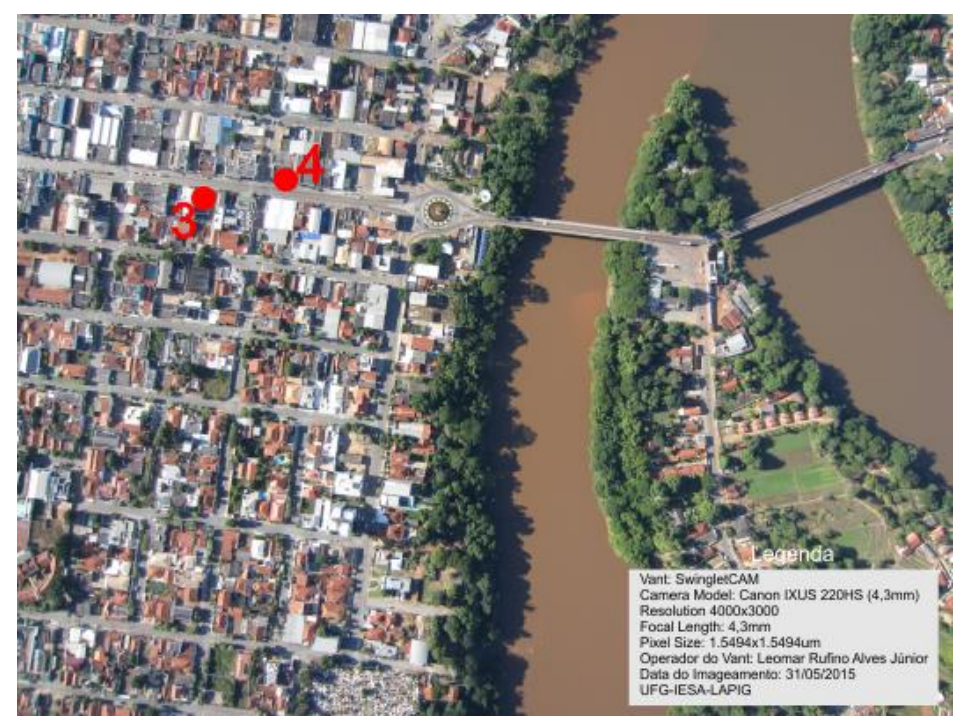

Figura 5 - Imagem dos os pontos 3 e 4

Fonte: Romário Rosa de Sousa (2015).

Quanto ao ponto 4 (quatro), há também um fluxo intenso de pessoas em virtude de estabelecimentos como lojas, bancos, lanchonetes, bares, casas noturnas, clínicas, consultórios médicos, postos de saúde, igrejas, farmácias, residências, e por estar em uma via de acesso a vários locais turísticos como as praias de água doce nos Rios Araguaia e Garças, nos municípios de Aragarças-GO, Pontal do Araguaia-MT e Barra do Garças-MT, e por dar acesso ao parque municipal das águas quentes, e ao parque Salomé José 
Rodrigues. Portanto, as proximidades do ponto 4, conforme a figura 5, é frequentado por pessoas de todas as faixas etárias.

Podem-se constatar na Tabela 3, os níveis de critério para ambientes externos, de acordo com os horários diurno e noturno. A norma NBR 10.151 (2000) estabelece que os períodos diurno e noturno possam ser definidos pelas autoridades de acordo com os hábitos da população. No entanto, o período noturno não deve começar depois das 22 horas e não deve terminar antes das 7 horas. No caso de domingos e feriados, o término do período noturno não deve ser anterior às 21 horas.

Tabela 3 - Nível de critério de avaliação - NCA para ambientes externos urbanos

\begin{tabular}{lcc}
\hline Tipos de áreas & $\begin{array}{c}\text { Diurno } \\
(\mathrm{dB}(\mathrm{A}))\end{array}$ & $\begin{array}{c}\text { Noturno } \\
(\mathrm{Db}(\mathrm{A}))\end{array}$ \\
\hline Área de sítios e fazendas & 40 & 35 \\
Área estritamente residencial urbana ou hospitais ou de escolas & 50 & 45 \\
Área mista, predominantemente residencial & 55 & 50 \\
Área mista, com vocação comercial e administrativa & 60 & 55 \\
Área mista, com vocação recreacional & 65 & 55 \\
Área predominantemente industrial & 70 & 60 \\
\hline
\end{tabular}

Organizado e adaptado por: Romário Rosa de Sousa (2015)

Fonte: NBR 10.151, 2000.

Em ambos os pontos de observações ao longo da Avenida Ministro João Alberto o adensamento urbano e grande com edificações comerciais, já para o seu entorno existe o prosseguimento para outros bairros compostos por casas, prédios comerciais, escolas, associações, bancos, igrejas, conforme podem ser visualizados nas figuras 4 e 5 , destaca-se que a parte central e no entorno a pavimentação foi realizada por asfalto e encalçadamento feito por concreto.

Nas Resoluções, $\mathrm{n}^{\circ} 1$ e n² 2, de 11 de fevereiro de 1993, o CONAMA estabeleceu limites máximos de ruído para veículos automotores em aceleração e na condição de parado. Levaram-se em conta, nessas Resoluções, os prejuízos à saúde física e mental, particularmente à audição que esses ruídos podem causar, e, portanto, a necessidade de se reduzir a poluição sonora nos centros urbanos. Ainda, considerou-se o fato de os veículos automotores rodoviários serem as principais fontes de ruído no meio ambiente, e o uso de tecnologias adequadas para o controle da poluição sonora e os objetivos do Programa Nacional de Educação e Controle da Poluição Sonora (BRASIL, 1993a, b).

O tráfego rodoviário é composto por um grande número de veículos que circulam em intervalos de tempo irregulares com diferentes velocidades, acelerações e tipos de potência motriz. Trata-se, então, da sobreposição de diferentes fontes sonoras com 
Poluição sonora na Avenida Ministro João Alberto na cidade de Barra do Garças-MT Romário Rosa de Sousa

características distintas (COELHO, 1995). Suas características fazem com que, em alguns momentos, o ruído seja considerado como contínuo e, em outros, como intermitente, dependendo do fluxo de veículos ser grande ou pequeno. O som pode ser também classificado, além de contínuo e de intermitente, como flutuante (irregular), impulsivo, tonal e de baixa frequência (BRÜEL \& KJÆR, 2000), especificações que indicam características sonoras especiais.

No Gráfico 1, percebeu-se que os níveis de ruídos registrados nas observações diária ultrapassaram esse limite, sendo o maior valor registrado pelo veículo automotor caminhão guincho, com aproximadamente 98,0 decibéis. Seguiram-se o caminhão, a carreta, o ônibus, a motocicleta, o carro de passeio e a caminhonete, este veículo automotor a menor fonte emissora de ruído, registrando aproximadamente 89,0 decibéis.

A propagação sonora, portanto, consiste na transmissão da energia acústica a partir do movimento vibratório das partículas componentes do meio que, após serem inicialmente perturbadas, passam a atuar como fontes elementares (Princípio de HuyghesFresnel), perturbando novas partículas por colisões quase elásticas e assim consecutivamente, até que a energia acústica seja plenamente consumida, pelas perdas dissipativas que ocorrem durante o processo (FUSINATO, 2005).

Conforme diagnosticado na Tabela 2 anteriormente e comprovado no Gráfico 1, as mensurações dos níveis de ruído em veículos ficaram bem acima do permitido por lei no perímetro urbano.

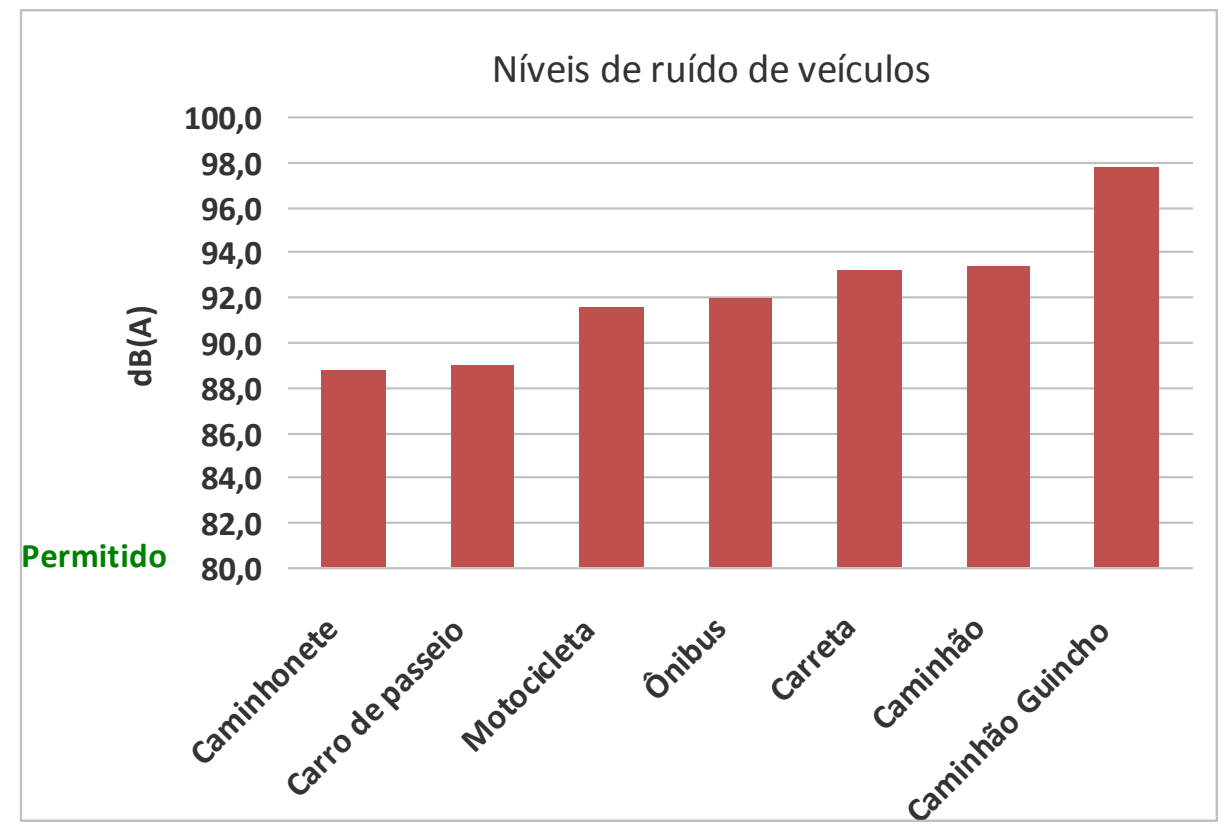

Gráfico 1 - Mensurações dos níveis de ruído em veículos [valores em $\mathrm{Db}(\mathrm{A})$ ].

Fonte: Romário Rosa de Sousa (2015). 
Os níveis de ruídos diagnosticados merecem preocupação, uma vez que estão acima do permitido, $80 \mathrm{~dB}(\mathrm{~A})$ para veículos e $50 \mathrm{~dB}(\mathrm{~A})$ para ambientes urbanos, respeitando a NBR 10.151, que procura garantir o conforto da comunidade em termos ocupacionais, dispondo sobre o tempo máximo de exposição ao ruído, estabelecido pelo Ministério do Trabalho e Emprego, que é de $85 \mathrm{~dB}(\mathrm{~A})$, para um período de 8 horas (BRASIL, 1978). Desse modo, conforme os registros demonstrados no gráfico 1, os níveis de pressão sonora presentes nos pontos de coleta de dados na Avenida Ministro João Alberto estão todos acima do tolerável e geram riscos de problemas de perda auditiva em trabalhadores que atuem e que fiquem em exposição nos locais medidos.

Segundo a World Health Organization (2016), exposição ao ruído ambiente é responsável por uma série de efeitos sobre a saúde, incluindo o aumento do risco de doença isquêmica do coração, bem como distúrbios do sono, disfunção cognitiva, entre crianças, aborrecimento, riscos para a saúde mental, relacionados com o stress, e zumbido. Em conjunto, estes riscos em países europeus de alta renda são responsáveis por uma perda de 1-1.6 milhões de anos de vida ajustados pela incapacidade (DALY) - uma medida padronizada de anos de vida saudável perdidos por doença, invalidez ou morte precoce.

Enquanto o tráfego rodoviário é o problema relacionado com o ruído mais difundido, as crianças que vivem em áreas com elevado ruído de aeronaves atrasaram as idades de leitura, níveis de atenção pobres, e altos níveis de estresse. Reduzindo os volumes de tráfego reduz a exposição de ruído, bem como poluentes atmosféricos. Os valores mais baixos de tráfego em bairros pode gerar outros co-benefícios económicos e sociais, tais como valores de propriedade mais elevados e aumento dos níveis de atividade rua de pedestres e interação social World Health Organization (2016).

De acordo com a Lei complementar no 150 de 02 de maio de 2013, seção V, artigo 216, \ I, do Código do Meio Ambiente de Barra do Garças-MT, diz que poluição sonora: toda emissão de som, vibração ou ruído que, direta ou indiretamente, seja ofensiva ou nociva à saúde física e mental, à segurança e ao bem estar do indivíduo ou a coletividade, ou transgrida as disposições fixadas na lei.

Percebe-se que o controle do ruído urbano só terá resultados satisfatórios quando a comunidade, juntamente com as empresas e o município, agirem juntos. Campanhas de conscientização ambiental e de informação ao consumidor farão com que a população valorize os produtos mais silenciosos. As novas legislações e os selos que comprovam a qualidade dos produtos estão estimulando as empresas a produzir levando em conta os 
impactos negativos do ruído (TEIXEIRA; TENENBAUM, 2000a). O combate à poluição sonora requer, assim, soluções técnicas, educativas e legais (BERISTÁIN, 1998).

A Resolução n. 2, de 08 de março de 1990, instituiu, em caráter nacional, o Programa Nacional de Educação e Controle da Poluição Sonora - Silêncio. Este programa tem como objetivo ensinar e conscientizar a população e capacitar técnicos para receber denúncias e tomar providências de combate à poluição sonora, além de incentivar a produção de equipamentos com menor intensidade de ruído, sendo coordenado pelo Instituto Brasileiro do Meio Ambiente e dos Recursos Naturais Renováveis (IBAMA) (BRASIL, 1990b, p. 45).

Sistemas eletrônicos como fones de ouvido de aparelhos celular, utensílios domésticos, meios de transporte, construções, indústrias, atividades comerciais ou de prestação de serviços, igrejas, bares, casas noturnas e outros locais de diversão e vizinhança são algumas das fontes de ruído presentes no mundo atual. Além destas fontes, gera-se também ruído de forma indiscriminada, seja por ignorância ou para chamar atenção (BERISTÁIN, 1998).

O controle da poluição sonora nos centros urbanos deve envolver medidas que garantam a manutenção de níveis sonoros para diferentes situações, horários e locais, seja fiscalizando, legislando ou executando atividades relacionadas a este tema (ALVES; PIZZUTTI, 1998). Normalmente, o controle do ruído em comunidades é baseado em restrições de acordo com o zoneamento (uso do solo) e horário do dia. Zonas sensíveis ao ruído, em torno de hospitais e escolas, por exemplo, são criadas devido às condições sonoras especiais de que necessitam (CASALI, 2000).

\section{CONSIDERAÇÕES FINAIS}

A pesquisa empreendida permitiu perceber níveis elevados de ruídos em todos os horários do dia de sua realização, verificando níveis sonoros registrados acima do permitido para o trânsito de veículos, ou seja, de $80 \mathrm{~dB}(\mathrm{~A})$. Independendo do horário do dia, identificaram-se, nos pontos de aplicação da metodologia, níveis de pressão sonora superiores aos estabelecidos pela norma NBR 10.151 (2000) para áreas escolares, hospitalares ou residenciais, uma vez que o nível de critério de avaliação para estes ambientes, no horário diurno, é $50 \mathrm{~dB}(\mathrm{~A})$ em locais urbanos. Possibilitou-se, ainda, verificar quais veículos automotivos mais emitem ruídos ambientais, classificando-se, nessa 
ordem: caminhão guincho, caminhão, carreta, ônibus, motocicleta, carro de passeio e, por fim, caminhonete.

Constatou-se, ao longo das medições sonoras, uma grande porcentagem de veículos antigos e em precário estado de conservação que trafegam Avenida Ministro João Alberto e que contribuem grandemente com os altos níveis de ruído ambiental. No caso dos automóveis, devem ser feitas campanhas educativas incentivando sua correta manutenção. Já no caso dos veículos responsáveis pelo transporte coletivo, principalmente os ônibus, a prefeitura, ou o órgão responsável, deve fazer um controle rigoroso destas frotas verificando os níveis de emissão sonora, exigindo, sua manutenção periódica dos ou a sua substituição por veículos mais novos e silenciosos.

Sabe-se que a poluição sonora, em médio prazo, pode levar a um desgaste da população, gerando problemas de saúde, estresse, diminuição no rendimento, agressividade, entre outros. Assim, é necessário que se iniciem ações no sentido de planejar o desenvolvimento urbano, controlando a expansão da cidade e as fontes geradoras de ruído, penalizando quem superar os limites de emissão sonora prescritos nas normas e conscientizando as pessoas de que elas podem, também, contribuir para um ambiente mais saudável e agradável.

\section{REFERÊNCIAS}

ASSOCIAÇÃO BRASILEIRA DE NORMAS TÉCNICAS. NBR 10.151: Avaliação do nível do ruído em áreas habitadas visando o conforto da comunidade. Rio de Janeiro: ABNT, 2000. 4p.

ALVES, C.; PIZZUTTI, J. L. Controle de poluição sonora no Rio Grande do Sul. In: CONGRESSO IBEROAMERICANO DE ACÚSTICA, 1.; SIMPÓSIO DE METROLOGIA E NORMALIZAÇÃO EM ACÚSTICA DO MERCOSUL, 1.; ENCONTRO DA SOCIEDADE BRASILEIRA DE ACÚSTICA, 18., 1998, Florianópolis. Anais... Florianópolis: SOBRAC, 1998. p. 443-446.

BABISCH, W. Epidemiological studies of the cardiovascular effects of occupacional noise - a critical appraisal. Revista Noise \& Health, v. 1, n. 1, p. 24-39, 1998.

BERTOLI, S. R. Quanto custa o conforto ambiental? In: ENCONTRO NACIONAL DE TECNOLOGIA DO AMBIENTE CONSTRUíDO, 9., 2002, Foz do Iguaçu. Anais... Foz do Iguaçu: ENTAC, 2002. p. 485-494.

BERISTÁIN, S. El ruido es un serio contaminante. In: CONGRESSO IBEROAMERICANO DE ACÚSTICA, 1.; SIMPÓSIO DE METROLOGIA E NORMALIZAÇÃO EM ACÚSTICA DO MERCOSUL, 1.; ENCONTRO DA 
SOCIEDADE BRASILEIRA DE ACÚSTICA, 18., 1998, Florianópolis. Anais... Florianópolis: SOBRAC, 1998. p. 135-142.

BRESSANE, A.; SANTARINE, G. A.; MAURÍCIO J. C.; Poluição sonora: síntese de princípios fundamentais da teoria acústica. Revista Holos Environment, v. 10, n. 2, p. 223-237, 2010.

BRASIL. Constituição (1988). Constituição da República Federativa do Brasil. Brasília: Centro Gráfico do Senado Federal, 1988. 292p.

BRASIL. Ministério do Meio Ambiente. Comissão Nacional do Meio Ambiente, CONAMA. Resolução CONAMA n. 001/90. Dispõe sobre critérios de padrões de emissão de ruídos decorrentes de quaisquer atividades industriais, comerciais, sociais ou recreativas, inclusive as de propaganda política. Brasília: MMA. Disponível em: <http://www.mma.gov.br/port/conama/index.html>. Acesso em: 30 out. 2014.

BRASIL. Ministério do Meio Ambiente. Comissão Nacional do Meio Ambiente, CONAMA. Resolução CONAMA n. 002/90. Dispõe sobre o Programa Nacional de Educação e Controle da Poluição Sonora. Brasilia: MMA. Disponível em:

<http://www.mma.gov.br/port/conama/index.html>. Acesso em: 26 ago. 2003.

BRASIL. Ministério do Meio Ambiente. Comissão Nacional do Meio Ambiente, CONAMA. Resolução CONAMA n. 001/93. Dispõe sobre os limites máximos de ruídos, com o veículo em aceleração e na condição parado, para veículos automotores nacionais e importados, excetuando-se motocicletas, motonetas, triciclos, ciclomotores e bicicletas com motor auxiliar e veículos assemelhados. Brasília: MMA. Disponível em: <http://www.mma.gov.br/port/conama/index.html>. Acesso em: 26 ago. 2003.

BRASIL. Ministério do Meio Ambiente. Comissão Nacional do Meio Ambiente, CONAMA. Resolução CONAMA n. 002/93. Dispõe sobre os limites máximos de ruídos, com o veículo em aceleração e na condição parado, para motocicletas, motonetas, triciclos, ciclomotores e bicicletas com motor auxiliar e veículos assemelhados, nacionais e importados. Brasília: MMA. Disponível em:

< http://www.mma.gov.br/port/conama/index.html > . Acesso em: 26 ago. 2003.

BRASIL. Ministério das Cidades Conselho Nacional de Trânsito. Resolução CONTRAN n. 204/06. <http://www.denatran.gov.br/download/Resolucoes/Resolucao204 06.pdf>. Acesso em: 30 out. 2014.

BRÜEL \& KJÆR. Environmental noise. Denmark: Brüel \& Kjær Sound \& Vibration Measurement A/S, 2000. 65p.

COELHO, J. L. B.; VALADAS, B.; GUEDES, M. Ruído ambiente em Portugal. Acústica e Vibrações, Florianópolis, n. 18, p. 17-32, dez. 1996.

CONDE, V. A. ISO 14000: desenvolvendo o veículo verde. In: SIMPÓSIO BRASILEIRO DE ACÚSTICA VEICULAR, 3., 1995, São Paulo. Anais... São Paulo: SIBRAV, 1995. TB $25-1 / 7$.

COLLADOS, E. Prevención del impacto acústico de nuevos proyectos. In: CONGRESSO IBEROAMERICANO DE ACÚSTICA, 1; SIMPÓSIO DE METROLOGIA E 
NORMALIZAÇÃO EM ACÚSTICA DO MERCOSUL, 1; ENCONTRO DA SOCIEDADE BRASILEIRA DE ACÚSTICA, 18., 1998, Florianópolis. Anais... Florianópolis: SOBRAC, 1998. p. 169-177.

COSTABAL, H.; SEBALLOS, S. Modelo de gestión para control del ruido urbano. In: CONGRESSO BRASIL/ARGENTINA, 1.; ENCONTRO DA SOCIEDADE BRASILEIRA DE ACÚSTICA, 15, 1994, Florianópolis. Anais... Florianópolis: SOBRAC, 1994. p. 339-348.

FALETTY, P. Incidencia del ruido en la comunidad. In: CONGRESSO BRASIL/ARGENTINA， 1; ENCONTRO DA SOCIEDADE BRASILEIRA DE ACÚSTICA, 15, 1994, Florianópolis. Anais... Florianópolis: SOBRAC, 1994. p. 357-360.

FISCHER, F. M.; GOMES, J. R.; COLACIOPPO, S. Tópicos de saúde do trabalhador. São Paulo: Hucitec, 1989.

FONSECA, A. M. P. Perfil audiométrico de exames admissionais em trabalhadores da construção civil da Bahia. 2007. 88f. Dissertação (Mestrado em Fonoaudiologia) Pontifícia Universidade Católica de São Paulo, São Paulo, 2007.

FUSINATO, V. A. Mini-curso de acústica e ruídos. Apostila (Acústica e Vibrações). Departamento de Física, Universidade Estadual de Maringá, Paraná. 2005.

GARCIA, A. D. Ruido: el contaminante nuestro de cada dia. In: CONGRESSO MEXICANO DE ACÚSTICA, 1., 1994, Monterrey. Anais... Monterrey, 1994. p. 233-245.

GERGES, S. N. Y. Ruído: fundamentos e controle. 2. ed. Florianópolis: NR Editora, 2000. 676p.

GIERKE, H. E. V.; ELDRED, K. M. Efeitos do ruído no homem. Acústica e Vibrações, Florianópolis, n. 19, p. 2-29, jul. 1997.

LACERDA, A.; FIGUEIREDO, G.; MASSAROLO, J. N.; MARQUES, J. M. Achados audiológicos e queixas relacionadas à audição dos motoristas de ônibus urbano. Revista da Sociedade Brasileira de Fonoaudiologia, São Paulo, v. 15, n. 2, p. 161-166, 2010.

INSTITUTO BRASILEIRO DE GEOGRAFIA E ESTATÍSTICA (2014). Mato Grosso Barra do Garças-MT. Informações Estatísticas. Disponível em $<$ http:/ $/$ www.cidades.ibge.gov.br/xtras/perfil.php?lang=\&codmun $=510180 \&$ search $=$ mat o-grosso | barra-do-garcas >. Acesso em: 03 maio 2016.

IWATA, N.; YAMAMOTO, S.; KORENAGA, M.; NODA, S. Improved algorithms of seiscmic parameters estimation and noise discrimination in earthquake early warning. QR of RTRI, v. 56. n. 4, p. 291-298, nov. 2015.

NAGEM, M. P. Mapeamento e análise do ruído ambiental: diretrizes e metodologia. 2004. 133f. Dissertação (Mestrado em Engenharia Civil) - Universidade Estadual de

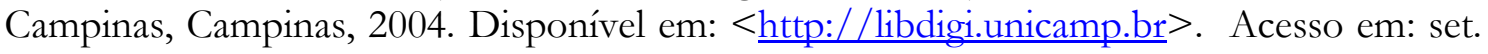
2014. 
MAIZ, J. J. F.; LEON, R. V. La problemática del ruido en al área metropolitana de la ciudad de Monterrey. In: CONGRESSO MEXICANO DE ACÚSTICA, 1., 1994, Monterrey. Anais... Monterrey, 1994. p. 261-264.

MACEDO, M. R. V.; SLAMA, J. G. Avaliação pós-ocupação acústica e a gestão ambiental urbana. In: ENCONTRO DA SOCIEDADE BRASILEIRA DE ACÚSTICA, 19., Belo Horizonte, 2000. Anais... Belo Horizonte: SOBRAC, 2000. p. 392-397.

MARCHETT, M. C.; CARVALHO, M. S. Ruídos na cidade de Londrina - Paraná. Revista RA'E GA, n. 23, p. 621-651, 2011.

MENDES, R. Patologia do trabalho. São Paulo: Atheneu, 1995.

RIOS, A. L. Efeito tardio do ruído na audição e na qualidade do sono em indivíduos expostos a níveis elevados. 2003. 194f. Dissertação (Mestrado em Clínica Médica) Universidade Estadual de Campinas, Campinas, 2007. Disponível em:

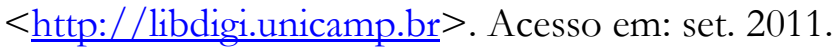

RIVAS, I. S. Contaminación ambiental por ruido. In: CONGRESSO MEXICANO DE ACÚSTICA, 1., 1994, Monterrey. Anais... Monterrey, 1994. p. 219-225.

ORGANIZAÇÃO MUNDIAL DA SAÚDE (OMS), Résumé D’orientation dês Directives D'IOMS Relatives Au Bruit Dans I'environmental (documento da internet), 2003. Disponível em: < http://www.who.int/research/en/>. Acesso em: 09 out. 2014.

PETIAN, A. Incomodo em relação ao ruído urbano entre trabalhadores de estabelecimentos comerciais no município de São Paulo. 2008. 126f. Tese (Doutorado em Ciências) - Universidade de São Paulo, São Paulo, 2008. Disponível em:

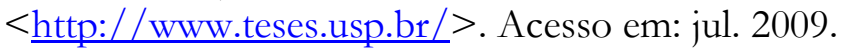

PRINZ, D. Tradução Luis Leitão. Urbanismo 1: projecto urbano. Lisboa: Presença, 1980.189p.

RANGEL, C. A.; ZANOTELLI, C. L. Do som ao ruído, a Poluição Sonora no Ambiente Urbano. In: ENCONTRO NACIONAL DE GEÓGRAFOS, 13., 2002, João Pessoa. Anais... Associação Brasileira de Geógrafos-AGB, 2002.

SANTOS, M. A. Questão do meio ambiente: desafios para a construção de uma perspectiva transdisciplinar. InterfacEHS - Revista de Gestão Integrada em Saúde do Trabalhador e meio Ambiente,v. 1, n. 1, p. 1-14, ago. 2006.

SMINKEY, L. Billion people at risk of hearing loss. World Health Organization WHO: Department for Management of Noncommunicable Diseases. Disponível em: $<$ http://www.who.int/mediacentre/news/releases/2015/ear-care/en/>. Acesso em: 03 maio 2015.

SOUSA, R. R.; NASCIMENTO, J. A.; NASCIMENTO, A. S. G.; PACHECO, A. B. D. Análises de notificações e multas como indicadores da poluição sonora na cidade de Cuiabá-MT. HYGEIA - Revista Brasileira de Geografia Médica e da Saúde, v. 14, n. 8, p. 101-114, jun. 2012. 
SIH, T. - A poluição sonora e a criança. In: SIH, T. (Org.). Manual de otorrinolaringologia pediátrica da Iapo, São Paulo: Iapo, 1997. p. 33 - 39.

SLAMA, J. G.; NIEMEYER, M. L. A. Estratégias para elaboração de uma legislação para o controle do ruído urbano em região de clima tropical úmido. In: CONGRESSO IBEROAMERICANO DE ACÚSTICA, 1.; SIMPÓSIO DE METROLOGIA E NORMALIZAÇÃO EM ACÚSTICA DO MERCOSUL, 1.; ENCONTRO DA SOCIEDADE BRASILEIRA DE ACÚSTICA, 18., 1998, Florianópolis. Anais... Florianópolis: SOBRAC, 1998. p. 499-502.

TEIXEIRA, S. G.; TENENBAUM, R. A. Zona sul do Rio de Janeiro: controvérsias e litígios quanto à intensificação de auditorias do projeto silêncio. In: ENCONTRO DA SOCIEDADE BRASILEIRA DE ACÚSTICA, 19, 2000, Belo Horizonte. Anais... Belo Horizonte: SOBRAC, 2000b. p. 422-427.

WORLD HEALTH ORGANIZATION, 2016. Noise - Health and sustainable development. Disponível em: < http://www.who.int/sustainabledevelopment/transport/health-risks/noise/en/>. Acesso em: 03 maio 2015.

ZANNIN, P. H. T.; SZEREMETTA, B. Avaliação da poluição sonora no parque Jardim Botânico de Curitiba, Paraná, Brasil. Cad. Saúde Pública, Rio de Janeiro, v. 19, n. 2, p. 683-686, mar./abr. 2003. 